\title{
PERBANDINGAN ANALISA USABILITY DESAIN USER INTERFACE PADA WEBSITE SHOPEE DAN BUKALAPAK MENGGUNAKAN METODE HEURISTIC EVALUATION
}

\author{
${ }^{1}$ Siti Auliaddina \\ ${ }^{2}$ Adiva Arini Puteri \\ ${ }^{3}$ Iedam Fardian Anshori \\ Teknik Informatika, Universitas Adhirajasa Reswara Sanjaya \\ Email : 'dinasuikoden2@gmail.com \\ 2 adivaarinip@gmail.com \\ ${ }^{3}$ iedam@ars.ac.id
}

\begin{abstract}
An e-commerce website which is a website for conducting buying and selling transactions must have an attractive User Interface (UI) in order to make many users interested in using their website in buying and selling transactions. The User Interface is one of the factors that determine the number of visitors to a website. User Interface is discussed in the discipline of HCI (Human and Computer Interaction) or also known as human and computer interaction. Because the User Interface is so important on a website, a Usability Test is needed, to check how efficient and effective the website's User Interface is. In this study, the authors compare the Usability Tests of two e-commerce websites, namely Bukalapak and Shopee, which are 2 of the 3 biggest e-commerce websites in Indonesia. The method used is the Heuristic method which all of its characteristics can be used to test all the characteristics of an efficient and effective User Interface. The research was conducted by distributing questionnaires to 70 correspondents. From the results of this study, it was found that the Shopee website was more effective and efficient to use compared to the Bukalapak website.
\end{abstract}

Keywords : Heuristic Method, Usability Test, Human and Computer Interaction, User Interface, Website

\begin{abstract}
Abstrak
Website e-commerce yang merupakan website untuk melakukan transaksi jual beli haruslah memiliki User Interface (UI) yang menarik agar dapat membuat banyak user tertarik menggunakan websitenya dalam transaksi jual beli. User Interface merupakan salah satu faktor yang menentukan banyaknya pengunjung pada suatu website. User Interface dibahas dalam ilmu disiplin HCI (Human and Computer Interaction) atau biasa disebut juga interaksi manusia dan computer. Karena begitu pentingnya User Interface pada suatu web maka diperlukan Usability Test, untuk mengecek seberapa efisien dan efektifnya User Interface website tersebut. Dalam penelitian ini penulis melakukan perbandingan Usability Test dua website e-commerce yaitu Bukalapak dan Shopee yang merupakan 2 dari 3 besar website e-commerce terbesar di Indonesia. Metode yang digunakan adalah metode Heuristic yang semua karakeristiknya dapat digunakan untuk mengetest semua karakteristik User Interface yang efisien dan efektif. Penelitian dilakukan dengan menyebarkan kuesioner kepada 70 orang koresponden. Dari hasil penelitian ini didapat bahwa website Shopee lebih efektif dan efisien untuk digunakan diabndingkan dengan website Bukalapak.
\end{abstract}

Kata Kunci : Interaksi Manusia dan computer, Metode Heursitic, Usability Test, User Interface, Website.

\section{Pendahuluan}

Dengan berkembangnya teknologi saat ini, pemasaran atau transaksi jual beli dapat dilakukan melalui website. Website adalah kumpulan berbagai informasi yang terdiri dari halaman-halaman web yang saling terhubung 
satu sama lain yang dibuat atau disediakan secara perorangan, kelompok atau pun organisasi [9].

Situs web atau website harus menampilkan visual yang menarik dan tentunya harus berfungsi sesuai dengan kebutuhan pengguna.

User Interface yang atau biasa disingkat dengan $U I$ adalah rangkaian tampilan atau visual grafis yang dapat dimengerti oleh pengguna (user) komputer dan diprogram dengan baik dan benar sehingga dapat terbaca oleh sistem operasi komputer dan beroperasi sebagaimana mestinya [2].

User Interface merupakan salah satu faktor yang menentukan banyaknya pengunjung pada suatu website. Karena pengunjung website berinteraksi dengan logika pemrograman website tersebut melalui User Interface [2].

Sehingga membuat User Interface menjadi hal sangat penting mengingat semakin efektif dan efisien suatu desain, maka user atau pengunjung website pun akan semakin betah berlama-lama di website tersebut.

Ilmu disiplin yang digunakan dalam penelitian ini adalah HCI (Human and Computer Interaction) atau biasa disebut juga interaksi manusia dan komputer.

Interaksi manusia dan komputer adalah suatu disiplin ilmu yang mempelajari komunikasi atau interaksi yang dilakukan antara pengguna dan sistem, baik itu merupakan sistem dalam komputer ataupun sistem lain yang ada pada kehidupan seharihari [12].

Terdapat banyak cara atau metode yang dapat digunakan untuk mengevaluasi Usability desain User Interface sebuah website. Salah satunya adalah metode Heuristic [4].

Pada penelitian kali ini penulis menggunakan metode heuristik. Heuristik adalah suatu metode dalam melakukan pemeriksaan mengenai kemudahan penggunaan (Usability) serta membantu mencari atau mengidentifikasikan masalahmasalah pada antarmuka atau User Interface suatu perangkat lunak [8].

Sepuluh aspek yang dinilai dalam metode Heuristics Evaluations menurut Jakob Nielsen adalah sebagai berikut [7]:

1) Visibilitas status sistem

2) Kecocokan antara sistem dan dunia nyata.
3) Kontrol dan kebebasan pengguna

4) Standarisasi dan konsistensi

5) Pemahaman daripada ingatan

6) Fleksibilitas dan efisiensi pengguna

7) Pencegahan kesalahan

8) Estetika dan desain minimalis

9) Membantu pengguna untuk mengenali, mendiagnosa, dan memulihkan dari error

10) Bantuan dan dokumentasi

Dipilihnya metode heuristik ini dikarenakan metode ini dianggap lebih valid, karena menguji atau menanyakan langsung pengalaman pengguna dalam mengakses website yang dijadikan objek.

Objek yang diuji-cobakan dalam penelitian kali ini ada dua, yaitu website $e$ commerce Shopee dan website e-commerce Bukalapak. Yang nantinya akan diperbandingkan mulai dari ke-efektifan dan ke-efisienan dua website e-commerce tersebut.

Dipilihnya dua website e-commerce tersebut karena dua website e-commerce tersebut termasuk 3 besar website e-commerce terbesar di Indonesia.

Menurut data dari iprice.co.id, pada kuartal IV tahun 2020, Shopee menempati posisi pertama dengan rata-rata kunjungan website bulanan sebesar 129,3 juta sedangkan Bukalapak menempati posisi ketiga dengan rata-rata kunjungan website bulanan sebesar 38,58 juta.

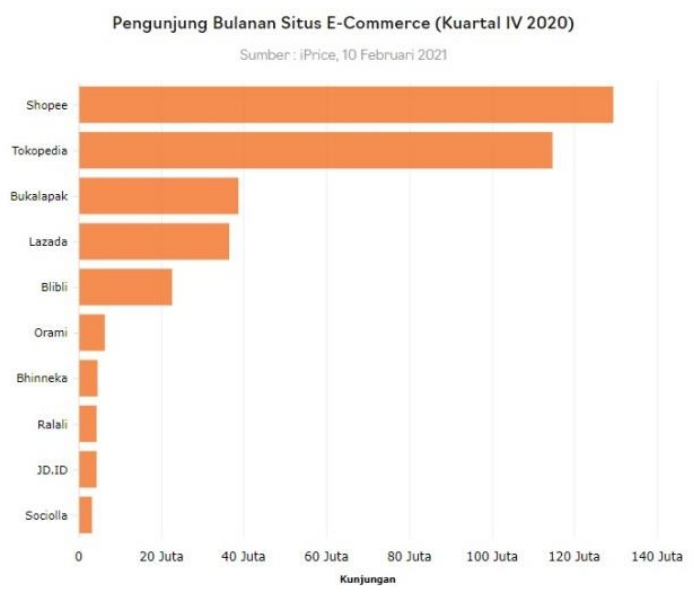

Gambar 1. Grafik jumlah pengunjung website ecommerce Indonesia kuartal IV tahun 2020 [iprice.co.id 2021]

Tujuan dilakukannya penelitian ini adalah, untuk mengetahui perbandingan kelebihan dan kekurangan dari masing-masing objek sehingga bisa menjadi bahan evaluasi untuk perbaikan kedepannya. 


\section{Metode Penelitian}

Dalam penelitian ini metode yang digunakan adalah studi literatur tentang interaksi manusia dan komputer, serta teori "Heuristics Evaluation" Jakob Nielsen dan Rolf Molich yang akan dijadikan sebagai acuan dalam melakukan evaluasi Usability desain User Interface.

Yang kemudian dilanjutkan dengan memberikan kuesioner koresponden yang berjumlah sebanyak 70 orang untuk menilai desain User Interface melalui pertanyaan yang berdasar dari metode "Heuristic Evaluation".

Pertanyaan-pertanyaan kuesioner berdasarkan dari 10 karakteristik Heuristic. Setiap peranyaan merupakan pilihan ganda yang terdiri dari 4 pilihan ganda, yang nantinya dilakukan proses scoring berdasarkan jawaban yang dipilih. Dibawah ini merupakan table dari scoring pilihan ganda kuesioner yang disebar.

Tabel 1 Scoring pilihan ganda

\begin{tabular}{|l|c|}
\hline \multicolumn{1}{|c|}{ Pilihan Jawaban } & Nilai \\
\hline Sangat Baik & 4 \\
\hline Baik & 3 \\
\hline Cukup & 2 \\
\hline Kurang & 1 \\
\hline Buruk & 0 \\
\hline
\end{tabular}

Setelah semua jawaban dari para responden telah terkumpul maka akan diproses untuk dilakukan penarikan kesimpulan dan saran untuk tujuan pengembangan sistem Website Shopee dan Bukalapak atau bagi Website lainnya.

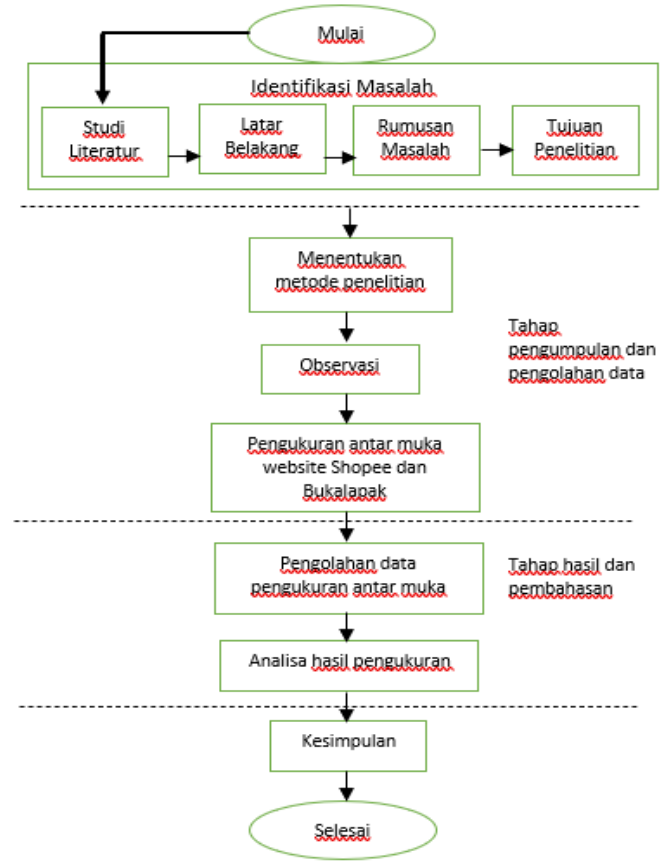

Gambar 2. Alur Metode Penelitian [2]

\section{Hasil dan Pembahasan}

Dibawah ini merupakan table hasil kuesioner Usability Test User Interface website Bukalapak dan Shopee menggunakan metode Heuristic yang di berikan kepada 70 korespoden.

Tabel 2 Hasil Kuesioner

\begin{tabular}{|c|c|c|c|c|}
\hline \multirow{2}{*}{ No } & \multirow{2}{*}{ Variabel } & \multirow{2}{*}{ Instrumen } & \multicolumn{2}{|c|}{ Nilai } \\
\hline & & & Bukalapak & Shopee \\
\hline \multirow[t]{2}{*}{1} & \multirow[t]{2}{*}{$\begin{array}{c}\text { Visibilitas } \\
\text { status sistem }\end{array}$} & $\begin{array}{l}\text { Kejelasan } \\
\text { Informasi yang } \\
\text { ditampilkan } \\
\text { pada website. }\end{array}$ & 2,66 & 3,27 \\
\hline & & $\begin{array}{l}\text { Proses umpan } \\
\text { balik yang } \\
\text { dilakukan pada } \\
\text { website tidak } \\
\text { membutuhkan } \\
\text { waktu yang } \\
\text { lama. }\end{array}$ & 2,43 & 2,84 \\
\hline \multirow[t]{3}{*}{2} & \multirow{3}{*}{$\begin{array}{c}\text { Kecocokan } \\
\text { antara sistem } \\
\text { dan dunia } \\
\text { nyata }\end{array}$} & $\begin{array}{l}\text { Pemilihan } \\
\text { warna yang } \\
\text { sesuai. }\end{array}$ & 2,63 & 3,11 \\
\hline & & $\begin{array}{l}\text { Penggunaan } \\
\text { tata bahasa } \\
\text { yang baik. }\end{array}$ & 2,73 & 3,16 \\
\hline & & $\begin{array}{l}\text { Penggunaan } \\
\text { gambar yang } \\
\text { komunikatif }\end{array}$ & 2,53 & 3,21 \\
\hline \multirow[t]{2}{*}{3} & \multirow[t]{2}{*}{$\begin{array}{c}\text { Kontrol dan } \\
\text { kebebasan } \\
\text { pengguna }\end{array}$} & $\begin{array}{l}\text { Pembatalan } \\
\text { sebuah } \\
\text { transaksi }\end{array}$ & 2,40 & 2,96 \\
\hline & & $\begin{array}{l}\text { Kemudahan } \\
\text { dalam navigasi }\end{array}$ & 2,58 & 3,18 \\
\hline
\end{tabular}




\begin{tabular}{|c|c|c|c|c|}
\hline 4 & $\begin{array}{l}\text { Konsistensi } \\
\text { dan standard }\end{array}$ & $\begin{array}{l}\text { Konsistensi } \\
\text { dalam } \\
\text { penulisan }\end{array}$ & 2,73 & 3,16 \\
\hline 5 & $\begin{array}{l}\text { Pencegah } \\
\text { kesalahan }\end{array}$ & $\begin{array}{l}\text { Pencegahan } \\
\text { penggunaan } \\
\text { dalam membuat } \\
\text { kesalahan }\end{array}$ & 2,66 & 2,98 \\
\hline 6 & $\begin{array}{l}\text { Pemahaman } \\
\text { daripada } \\
\text { ingatan }\end{array}$ & $\begin{array}{l}\text { Kejelasan } \\
\text { penggunaan } \\
\text { simbol dan } \\
\text { bahasa }\end{array}$ & 2,40 & 2,98 \\
\hline 7 & $\begin{array}{c}\text { Fleksibilitas } \\
\text { dan } \\
\text { kenyamanan } \\
\text { pengguna }\end{array}$ & $\begin{array}{l}\text { Sistem yang } \\
\text { ada } \\
\text { mempermudah } \\
\text { dan } \\
\text { mempercepat } \\
\text { pengguna } \\
\text { dalam } \\
\text { melaksanakan } \\
\text { setiap tugas }\end{array}$ & 2,51 & 3,16 \\
\hline \multirow[t]{2}{*}{8} & \multirow[t]{2}{*}{ Design } & $\begin{array}{l}\text { Pengelompokan } \\
\text { informasi } \\
\text { barang }\end{array}$ & 2.58 & 3,26 \\
\hline & & $\begin{array}{l}\text { Pemilihan } \\
\text { ukuran font dan } \\
\text { background }\end{array}$ & 2,64 & 3,10 \\
\hline 9 & $\begin{array}{c}\text { Membantu } \\
\text { pengguna } \\
\text { untuk } \\
\text { mengenali, } \\
\text { mendiagnosa, } \\
\text { dan } \\
\text { memulihkan } \\
\text { dari error }\end{array}$ & $\begin{array}{l}\text { Recovery } \\
\text { System }\end{array}$ & 2,46 & 3,00 \\
\hline \multirow[t]{2}{*}{10} & \multirow[t]{2}{*}{$\begin{array}{l}\text { Bantuan dan } \\
\text { dokumentasi }\end{array}$} & $\begin{array}{l}\text { Riwayat } \\
\text { transakasi } \\
\text { penjualan } \\
\text { maupun } \\
\text { pembelian }\end{array}$ & 2,60 & 3,36 \\
\hline & & $\begin{array}{l}\text { Bantuan ketika } \\
\text { terjadi } \\
\text { kesalahan atau } \\
\text { komplain }\end{array}$ & 2,46 & 3,00 \\
\hline
\end{tabular}

Koresponden yang terdiri dari 70 orang itu terdiri dari 58,57\% perempuan dan $42,43 \%$ laki-laki, selain itu background Pendidikan dari koresponden tersebuat berbeda-beda dan terdapat $31,43 \%$ orang yang memiliki background $I T$ sedangkan sisanya bukan.

Dari Hasil table diatas dapat terlihat bahwa dari semua karakteistik Heuristic yang diuji, website Shopee lebih unggul dibanding dengan website Bukalapak. Berdasarkan dari hasil kuesioner User Interface website Shopee lebih mudah, menarik dan nyaman unuk digunakan atau lebih user friendly dibandingkan dengan website Bukalapak. Point-point yang harus paling diperhatikan oleh website Bukalapak berdasarkan hasil table adalah pembatalan transaksi, dan kejelasan dalam penggunaan symbol dan tulisan dalam website Bukalapak. Sedangkan untuk website Shopee hal yang harus paling diperhatikan adalah waktu yang dibutuhkan untuk melakukan proses umpan balik terhadap user.

\section{Kesimpulan}

Dari hasil pembahasan diatas dapat disimpulkan bahwa Website Shopee lebih efektif dan efisien serta nyaman dan mudah digunakan atau lebih user friendly dibandingkan dengan website Bukalapak. Semua karakteristik Heuristic website Shopee lebih unggul dibandingkan website Bukalapak, sehingga diharapkan website Bukalapak dapat mengevaluasi kekurangan terutama di dua point karakteristik yaitu pembatalan transaksi, dan kejelasan dalam penggunaan symbol dan tulisan.

\section{DAFTAR PUSTAKA}

[1] Ali, Amir ., Pramana, Edwin., \& Tjandra, Suhatati.(2016). Evaluasi Heuristik Pada Web Based Learning Untuk Meningkatkan Aspek Usability Sistem. Jurnal Insand Comtech Vol.1 no.1, 17-26

[2] Aziza, Rifda. F. A \& Hidayat, Y.T. (2019). Analisa Usability Desain User Interface Pada Website Tokopedia Menggunakan Metode Heuristics Evaluation. Jurnal TEKNOKOMPAK Vol.13 no.1, 7-11

[3] Caesaron, Dino. (2015). Evaluasi Heuristic Desain Antar Muka (Interface) Portal Mahasiswa (Studi Kasus Portal Mahasiswa Universitas X). Jurnal Metris Vol. 16 no.1, 914

[4] Geasela, Yemima. M. , Ranting, Pranchis., \& Andry, Johannes.F. (2018). Analisis User Interface Terhadap Website Berbasis ELearning Dengan Metode Heuristic Evaluation. Jurnal Informatika Vol.5 no.2,270-277

[5] Islam, Khoirul \& Rahayu, Dewi. A. (2018). Evaluasi Antarmuka Website Tokopedia menggunakan Metode Heuristic. Jurnal ENERGY Vol.8 no.1, 33-38 
[6] Martanto. Analisis User Experience Untuk Perancangan User Interface Indigoes Menggunakan Metode Kansei Engineering

[7] Nielsen, J. and Molich, R., 1990, March. Heuristic evaluation of User Interfaces. In Proceedings of the SIGCHI conference on Human factors in computing systems (pp. 249256). ACM.

[8] Oktabareki, Prematara. (2019). Analisis UI/UX Pada Sistem Informasi Akademik Universitas Sriwijaya Dengan Menggunakan Metode Heuristic Evaluation [Skripsi]. Palembang (ID) Universitas Sriwijaya

[9] Rochmawati, Irma. (2019). Analisis User Interface Iwaerup.com . Jurnal Visualita Vol.7 no. $2,31-44$

[10] Savitri, Peti \& Ispani, Muhammad. (2015). Review Desain Interface Aplikasi SOPPOS Menggunakan Evaluasi Heuristik. Jurnal SIMETRIS Vol. 6 no.1, 95-100

[11] Siregar, Mareta. , Rokhmawati, Retno.I. , \& Az-Zahra, Hanifah. M. (2019). Evaluasi Usability dan Pengalaman Pengguna Website Zenius.net Menggunakan Metode TUXEL : A Technique for User Experience Evaluation in e-Learning. Jurnal Pengembangan Teknologi Informasi dan Ilmu Komputer Vol.3 no.5, 5058-5067

[12] Sudarmawan, D.A., 2007. Interaksi Manusia \& Komputer. Yogyakarta: Andi Offset.

[13] Waralalo, Mumtaz. H. (2019). Analisis User Interface (UI) Dan User Experience (UX) Pada AIS UIN Jakarta Menggunakan Metode Heuristic Evaluation Dan Webuse Dengan Standar ISO 13407[Skripsi]. Jakarta (ID): Universitas Islam Negeri Syarif Hidayatullah 